\title{
Educación campesina: las dimensiones pedagógico-políticas en la formación de la CLOC-VC y la UST como experiencia de lucha
}

Peasant Education: The Pedagogical and Political Dimensions in the Formation of the CLOC-VC and the UST as a Struggle Experience

Educação Camponesa: as Dimensões Pedagógico-Políticas na Formação da CLOC-VC e da UST como uma Experiência de Luta

Oscar Humberto Soto* iD orcid.org/0000-0003-1059-3885

Para citar este artículo: Soto, O.H. (2020). Educación campesina: las dimensiones pedagógicopolíticas en la formación de la CLoc-vc y la ust como experiencia de lucha. Revista Colombiana de Educación l(80), 355-376. https://doi.org/10.17227/rce.num80-11016

\section{(c) $(1) \Theta$}

Recibido: 23/12/2019

Evaluado: 29/03/2020

* Especialista en Epistemologías del Sur (Clacso). Jefe de Trabajos Prácticos de la Cátedra Teoría Política de la Licenciatura en Trabajo Social de la FCPyS, Universidad Nacional de Cuyo, Mendoza, Argentina. Correo electrónico: sotooscarhumberto@gmail.com 


\section{Resumen}

En este artículo de investigación analizamos los orígenes y la articulación de las comunidades que conforman la cLoc-vc, con especial atención en la experiencia de resistencia de la ust entre los años 2010 y 2019. Buscamos aquí dar cuenta del carácter político de las prácticas campesinas en las que los proyectos pedagógicos afloran como horizonte de sentido; para tal fin, reafirmamos que el recorrido del campesinado argentino contiene modalidades de insumisión en clave de las pedagogías promovidas por la cLoc-vc. Este trabajo sigue una metodología de investigación militante y situada, con el objeto de registrar la potencialidad transformadora de los movimientos sociales del mundo rural a partir de sus propuestas de educación y formación campesina.

\section{Palabras clave}

pedagogía crítica; espacio

rural; organizaciones

internacionales; escuela rural educación popular

\section{Keywords}

critical pedagogy; rural environment; international organizations; rural schools; popular education

\begin{abstract}
In this research article we analyze the origins and the articulation of the communities that make up the cLoc-Vc, focusing in the experience of resistance of the ust between 2010 and 2019. We seek to account for the political character of peasant practices in which the pedagogical projects emerge as a logical horizon. For this purpose, we reaffirm that the path of the Argentine peasantry contains modalities of insubordination in terms of the pedagogies promoted by the cLoc-Vc. This work follows a militant and situated research methodology. In the end, we register the transforming potential of rural social movements from their proposals of peasant education.
\end{abstract}

\section{Resumo}

Neste artigo de pesquisa analisamos as origens e a articulação das comunidades que compõem a cLoc-Vc, com especial atenção para a experiência de resistência da ust entre 2010 e 2019. Procuramos aqui dar conta do caráter político das práticas camponesas em que os projetos pedagógicos emergem como um horizonte de sentido; para o qual reafirmamos que o caminho do campesinato argentino contém modalidades de insubordinação em chave das pedagogias promovidas pela cLoc-vc. Este trabalho é abordado a partir de uma metodologia de pesquisa militante e situada, com o objetivo de registrar o potencial transformador dos movimentos sociais do mundo rural a partir de suas propostas de educação e formação camponesa.

\section{Palavras-chave}

pedagogia crítica; ambiente rural; organizações internacionais; escola rural; educação popular 


\section{Introducción}

La conformación de movimientos sociales y el surgimiento de organizaciones políticas en los sectores rurales de América Latina producen un conjunto de interrogantes teórico/políticos que desde las ciencias sociales a menudo se busca definir o caracterizar. En nuestro caso, procuramos identificar y describir de forma situada el despliegue de acciones, intervenciones y prácticas educativas llevadas a cabo por el colectivo que compone en la región la Coordinadora Latinoamericana de Organizaciones del Campo-Vía Campesina (CLOC-VC) a partir de la experiencia de la Unión de Trabajadores Rurales Sin Tierra (UST). El periodo de análisis aquí trabajado abarca los años 2010 a 2019, etapa de consolidación del proceso pedagógico de la Escuela Campesina de Agroecología (ECA) de la ust.

La problemática que se estudia, remite a un trabajo de investigación ${ }^{1}$ que busca, en última instancia, discernir mediante un enfoque teórico/ metodológico pertinente qué tipo de "prácticas" Ileva a cabo esta articulación de organizaciones conocida como CLOC-Vc. Se busca establecer desde la observación y el estudio de una experiencia situada cuáles son los signos político-pedagógicos que surgen en el desarrollo de esas intervenciones o accionar comunitario y rural; qué interpretan, a partir de sus prácticas, los sujetos que participan de esta articulación campesina regional, y últimas, qué podemos vislumbrar desde nuestra indagación al referirnos a dichas prácticas de educación campesina. Intuimos que es allí donde los proyectos pedagógicos afloran como horizonte de sentido político y contrahegemónico.

Partimos de una hipótesis inicial: en los territorios rurales existen relaciones políticas entre los sectores comunitarios y las clases dominantes, en las que operan lógicas de dominación y resistencias. El boliviano René Zavaleta Mercado (1982) Ilamaba a esto forma primordial, ese tipo de relación constantemente tensionada entre Estado y sociedad civil que envuelve el tipo de relaciones de producción posible. Descartamos por tanto en el presente texto un enfoque exclusivamente económico — generalmente asociado a las lecturas de la cuestión agraria latinoamericana-; antes bien, ponderamos una mirada teórico-política sobre la problemática

1 Este texto retoma parte de las conclusiones y el trabajo de campo realizados en el marco de la elaboración de la tesis de Maestría en Estudios Latinoamericanos Campesinado y contrahegemonía en América Latina. Un análisis sobre las prácticas prefigurativas de la Coordinadora Latinoamericana de Organizaciones del Campo-Vía Campesina y la disputa política entre los años 2013-2018 y el desarrollo de la beca de investigación: "Movimientos sociales y proyectos político-pedagógicos. La experiencia de la Escuela Campesina de Agroecología de la UST" otorgada por la Secretaría de Investigación y Publicación Científica. FCPys/uncuyo Res. 128/19 CD.

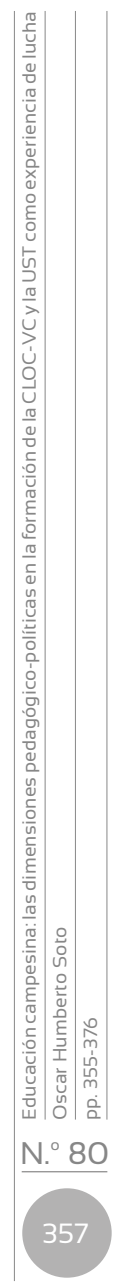


a indagar. En tal sentido, consideramos que repensar los movimientos campesinos y sus dimensiones pedagógicas convida a desentrañar el carácter de las disputas políticas, cognitivas y de sentido que se dan en los territorios.

A continuación, resaltaremos los orígenes y aportes teórico-políticos de la CLOC-VC y su propuesta pedagógica en clave de una construcción estrictamente política, siguiendo a Zavaleta Mercado. Seguidamente, retrataremos el macro-proceso que desarrolla la CLOC-vc a escala continental partiendo de la multiplicidad de sus espacios de formación política y agroecológica. Por último, después de contextualizar el traslado de la Secretaría Operativa de la CLOC a la Argentina, nos detenemos en el análisis de la experiencia de educación campesina en la Unión de Trabajadores Rurales Sin Tierra del Movimiento Nacional Campesino Indígena-Somos Tierra (UST-MNCI) en términos de una indagación más amplia respecto los procesos de subjetivación y resistencia campesino-indígena, asentados en la plenitud de relaciones de dominación vigentes, buscando dar cuenta de la potencialidad transformadora de los movimientos sociales del mundo rural a partir de sus propuestas de educación y formación campesina.

\section{Metodología}

El trabajo que a continuación exponemos se enmarca en un proceso de investigación militante, entendida como instancia de construcción de conocimiento fundamentada en las prácticas de los movimientos sociales y situados en una vinculación política con las experiencias relatadas. La investigación recorre metodológica y políticamente las experiencias del campesinado latinoamericano, pero centralmente es la CLOC-Vc la unidad de anclaje en la red de relaciones que conforman nuestra problemática. Asimismo, el desarrollo de la investigación está ajustado al lugar que ocupamos en el proceso de sistematización de las experiencias, ya que al formar parte del colectivo de educadores de la Escuela Campesina de Agroecología (ECA) y el Centro de Educación, Formación e Investigación Campesina (Cefic-Tierra), nuestro espacio/unidad de observación activa y participante será el UST-MNCl de Argentina, en consonancia con el marco espacial y temporal que hemos explicitado (2010-2019).

Para concretar esta propuesta, nos valemos de entrevistas (no estructuradas y en profundidad) a 10 militantes de la UST-MNCI ligados a la coordinación colectiva de la ECA y el Cefic-Tierra. Por otro lado, analizamos parte de la documentación colectiva producida por las organizaciones campesinas con relación a nuestro tema de investigación y la observación en territorio desarrollada en estos años estudiados. 


\section{Desarrollo}

\section{La lucha coordinada de las organizaciones campesinas}

El itinerario del pensamiento crítico latinoamericano ha sabido conjugar las reflexiones teóricas con la prepotencia de las prácticas sociohistóricas. Un emergente, por momentos olvidado, de esa línea de criticidad que reivindica la arena de las luchas políticas situadas es — por muchas razones - el boliviano René Zavaleta Mercado (Soto, 2019c). Para este intelectual marxista, siempre ha existido una consideración primaria de las construcciones políticas en América Latina (Zavaleta Mercado, 1982), antes que una mirada puramente economicista de los fenómenos periféricos de dependencia. Tal como sostiene Luis Tapia:

Este es uno de los pilares del trabajo de Zavaleta, en tanto no se dedica a un estudio de los procesos de trabajo, las estructuras económicas, el cambio tecnológico y el análisis de las tasas de explotación, sino que ofrece un análisis de la construcción política de los países, de la articulación de lo que Ilamó la "forma primordial", o la relación entre Estado y sociedad civil como una construcción histórica. (2016, p. 23)

Desde esa primacía de lo político nos disponemos a retomar aquí parte del despliegue de la disputa pedagógico-política campesina en la región. La CLOC es una instancia de articulación continental con 25 años de trabajo territorial en representación de luchas sociorrurales de movimientos campesinos, de trabajadores, indígenas y afrodescendientes de toda Latinoamérica. Esta coordinadora de movimientos cuenta con 84 organizaciones distribuidas en 18 países de América Latina y el Caribe, que en conjunto configuran una inédita experiencia de organización política de las clases subalternas que subsisten en los amplios paisajes de resistencia rural latinoamericanos (Soto, 2017). Su envergadura continental concatena disputas en amplios y diversos espacios de tensión política, en lo que a territorialidad y sujetos campesindios (Bartra, 2010) se refiere, esto es: desde la reforma agraria, la soberanía alimentaria y el comercio, derechos humanos, biodiversidad y recursos naturales, agricultura sostenible, género, pasando por temas de juventud rural, hasta migración y cuestiones de índole laboral son temas prioritarios de la coordinadora (CLOC, 2014a).

La constitución formal de la CLOC se da a partir de su primer congreso, realizado en Lima, Perú, del 21 al 25 de febrero de 1994. La emergencia y agitación política de ese año para las clases populares de Nuestra América y sus organizaciones de base se materializa, entre otras cosas, en el levantamiento zapatista en Chiapas, México (González Casanova, 2001) al tiempo que transcurre el segundo alzamiento indígena en Ecuador 
(Larrea Maldonado, 2004), las marchas de los cocaleros en Bolivia y las movilizaciones por la reforma agraria en Paraguay, Guatemala y Brasil, además de otros países. El antecedente directo del proceso de configuración inicial de la CLoc está relacionado con la experiencia de la Campaña Continental 500 Años de Resistencia Indígena, Negra y Popular que surgió en el marco de las "contracelebraciones" por el quinto centenario de la colonización y el despojo de 1492. Este fue un fenómeno novedoso de articulación y reunificación de movimientos y sujetos populares de todo el continente (León, 2019).

La lucha de la CLOC se articula inmediatamente con la propuesta que - ya en mayo de 1993, en una conferencia llevada a cabo en Mons, Bélgica - 46 representantes de organizaciones de campesinos, pequeños agricultores, pueblos indígenas y trabajadores del campo de varias regiones del mundo, habían creado bajo el nombre de La Vía Campesina (Rosset, 2016), y que contaba con el antecedente de las conversaciones dadas en Managua (Nicaragua) un año antes (CLOC, 2014b). Los orígenes mismos de La Vía Campesina (vc) se remontan a la década de los ochenta, por cuanto diversas organizaciones de base se arraigaban territorialmente: la Coordinadora Campesina Europea ( $\mathrm{CPE}$ ), así como la Asociación de Organizaciones Agrarias Centroamericanas (Asocode) y más tarde la misma CLOC en América Latina (CLOC, 2010).

En febrero de 1994, luego de varios años de trabajo conjunto, se realizó en Perú el Primer Congreso Latinoamericano de la CLoc, que contó con la presencia de organizaciones de todo el continente. Entre sus dirigentes se encontraba Evo Morales, quien, en representación de los cocaleros de Bolivia, fue uno de los fundadores de la Coordinadora. En este congreso, la CLOC estableció sus principios de lucha antiimperialista, anticapitalista, su compromiso en la lucha por la tierra y en la construcción de movimientos de masas y en la solidaridad permanente con la Revolución cubana y los procesos populares que avancen en el continente. Asimismo se propuso que las transformaciones en el campo debían darse en el marco de una transformación social que garantizara la libertad y los derechos de toda la clase trabajadora del campo y la ciudad (CLOC, 2015).

Más tarde, en abril de 1996, la cloc ingresó formalmente a La Vía Campesina. Ya en su segundo encuentro continental (Brasilia-1997) la Coordinadora se propone actuar sobre la acelerada penetración (y expansión territorial) del capital extranjero, los tratados de libre comercio, que obstruyen el esfuerzo productivo de los pueblos, la transferencia acelerada de los recursos naturales, la ola de privatizaciones y la introducción de políticas de ajustes que lanzan a la calle a millones de trabajadores junto con el recorte dramático de los presupuestos sociales (CLOC, 2015). Así es como la organización regional en el Caribe, Centroamérica, Andina y Cono Sur de la CLoc se transforma en la expresión continental de La Vía 
Campesina Internacional y constituye la fisonomía latinoamericana de un emergente potente de las resistencias al neoliberalismo y las políticas de la Organización Mundial del Comercio (OMC).

Bajo la consigna "Globalicemos la lucha, globalicemos la esperanza" el campesinado encuentra un espacio global de confluencia y es La Vía Campesina una de las organizaciones que se asumirá como interlocutor y voz autorizada de millones de campesinos/indígenas en lucha por la tierra. Será luego, entre otras cosas, a raíz de dicha juntura que vc logrará colocar el concepto de soberanía alimentaria ${ }^{2}$ como respuesta a la crisis alimentaria mundial, a partir de la cual la Organización de las Naciones Unidas para la Alimentación y la Agricultura (FAO, por sus siglas en inglés) revirtió su posición: de proponer solo agricultura industrial y corporativa para terminar con el hambre, a declarar el 2014 como Año Internacional de la Agricultura Familiar y reivindicar la agricultura campesina y familiar como componente fundamental de las alternativas para enfrentar la crisis civilizatoria (Giraldo y Rosset, 2016).

A partir del No al ALCA en el 2005, y del nuevo proceso abierto en el continente (Rauber, 2012), la CLOC-VC decidió dialogar con los gobiernos progresistas y populares de la región apoyando el proceso de integración de los pueblos. En ese derrotero, en octubre del 2012 se llevó a cabo una Asamblea Continental en Managua, en la que se ratificó que el vı Congreso de la CLOc se realizase en Argentina, y se estableció que la Secretaría Política fuese asumida por el Movimiento Nacional Campesino Indígena de Argentina (MNCI). El MNCI supo romper con el mito de que Argentina era una excepción en América Latina en la que, según la academia e incluso muchos sectores populares movilizados, militantes y movimientos sociales urbanos, no existían campesinos (CLOC, 2014a; Soto, 2019a).

La situación argentina es, pese a las reservas de cierta cosmovisión colonial-moderna de la urbanidad hegemónica, asimilable en muchas aristas de los sujetos rurales a la conformación orgánica de la CLOC. La Coordinadora refleja los cambios de una nueva ruralidad, que la liberalización económica y la apertura comercial había generado en la región. ${ }^{3}$ Siguiendo a Peter Rosset (2015), podemos señalar que sus organizaciones comprenden identidades campesinas (volcadas al trabajo agropecuario

2 El concepto de soberanía alimentaria fue acuñado por vc (en su II conferencia en Tlaxcala) y presentada junto con aliados de la sociedad civil en el marco de la Cumbre Mundial sobre la Alimentación (CMA) organizada por la FAO en Roma en 1996 (La Vía Campesina, 2007; Mançano Fernandes, 2017).

3 Entendemos la idea de una nueva ruralidad como esa imagen reciente que irrumpe en los parajes campesinos e indígenas de América Latina, donde logran coexistir grandes corporaciones económicas transnacionales volcadas a actividades extractivas y al agronegocio junto con mundos rurales precarizados. Allí se multiplican campesinos, productores medios y trabajadores rurales segmentados por los procesos de mecanización, grupos étnicos y nuevos excluidos (Giarraca, 2017). 
en unidades familiares y comunitarias), indígenas (cuyas luchas centrales remiten a la defensa autónoma de sus territorios y comunidades) e identificaciones más de corte proletario/rural (mayoritariamente familias sin tierra que se organizar para ocupar tierras y concretar formas de sindicalización). Martínez Torres y Rosset (2016) resumen las principales subjetividades que componen la cloc a partir de esos tres marcos identitarios (tabla 1).

\section{Tabla 1.}

Caracterización de los epistemes típicos de las organizaciones campesinas, indígenas y proletarias de la CLOC/VC

\begin{tabular}{|c|c|c|c|c|}
\hline $\begin{array}{c}\text { Marco } \\
\text { identitario }\end{array}$ & $\begin{array}{c}\text { Unidad de } \\
\text { organización }\end{array}$ & $\begin{array}{l}\text { Transmisión de } \\
\text { conocimientos }\end{array}$ & $\begin{array}{l}\text { Luchas } \\
\text { emblemáticas }\end{array}$ & $\begin{array}{l}\text { Fuente de afinidad } \\
\text { con la agroecología }\end{array}$ \\
\hline Indígena & Comunidad & $\begin{array}{l}\text { Codificados } \\
\text { en tradiciones } \\
\text { culturales }\end{array}$ & $\begin{array}{l}\text { Defensa del } \\
\text { territorio y } \\
\text { construcción de } \\
\text { autonomía }\end{array}$ & $\begin{array}{l}\text { Cosmovisión } \\
\text { indígena y cuidado } \\
\text { de la Madre Tierra }\end{array}$ \\
\hline Campesino & Familia & $\begin{array}{l}\text { Experiencial, } \\
\text { de campesino } \\
\text { a campesino }\end{array}$ & $\begin{array}{l}\text { Acceso a la } \\
\text { tierra, precios, } \\
\text { subsidios, crédito }\end{array}$ & $\begin{array}{l}\text { Costos de } \\
\text { producción } \\
\text { más bajos, } \\
\text { autoabastecimiento } \\
\text { en combinación } \\
\text { con el mercado }\end{array}$ \\
\hline Proletario & Colectivo & $\begin{array}{l}\text { Salones de clase y } \\
\text { asistencia técnica }\end{array}$ & $\begin{array}{l}\text { Ocupaciones de } \\
\text { tierra, huelgas y } \\
\text { transformación del } \\
\text { modelo Económico }\end{array}$ & $\begin{array}{l}\text { Ideología socialista } \\
\text { disputa con } \\
\text { el Capital }\end{array}$ \\
\hline
\end{tabular}

Fuente: adaptado de Martínez-Torres y Rosset (2016).

\section{La experiencia educativa de la CLOC-VC: IOS IALAS Como marco general de acción}

La educación campesina como proceso político objetivo y estrategia de formación subjetiva se ha tornado un aspecto central en la sedimentación de las resistencias campesindias latinoamericanas. En sentido estricto, la propuesta de re-existencia agroecológica (Soto, 2019a) es visible en la praxis educativa del movimiento campesino que se articula en torno a la CLOC-VC; concretamente, su proyecto pedagógico situado exhibe modalidades "ofensivas" en la reconfiguración de tales resistencias:

As epistemes das organizações da Lvc/CLOC conduzem a concepções de agroecologia em um horizonte comum, no entendimento de que a sua natureza ontológica é a consolidação da soberania alimentar como princípio político para a emancipação humana dos sujeitos do campo. Assim, ao longo da trajetória política das organizações no enfrentamento do capital transnacional há um vínculo indissociável entre 
território-sujeitos-educação-agroecologia, fundamental no avanço da pauta de luta articulada na região, em diálogo com as organizações membros dos outros continentes. (Rosset y Barbosa, 2017, p. 710)

Desde el 2005, con motivo del Foro Social Mundial en Porto Alegre, La Vía Campesina tomó la decisión de fortalecer las experiencias educativas ya existentes (Rosset, 2017), al tiempo que se propuso la construcción de institutos y escuelas de agroecología en todos los territorios de disputa de la CLOC. Entre los espacios de formación que ven la luz en estos años, a continuación podemos destacar algunos de relevancia (La Vía Campesina, 2015):

» La Escuela Latinoamericana de Agroecología (ELAA) en Paraná, Brasil

» El Instituto de Agroecología Latinoamericano Paulo Freire (IALA-Paulo Freire en Barinas, Venezuela.

» El Instituto de Agroecología Latinoamericano Guaraní (IALA-Guaraní) en Paraguay

» El Instituto de Agroecología Latinoamericano Amazónico (IALA-Amazónico) en Pará, Brasil.

» La Universidad Campesina SURI (Unicam Suri)/Argentina

» la Escuela Nacional de Agroecología (ENA)/Ecuador

»El IALA Centroamérica en Nicaragua

»El IALA/Haití

\#El IALA/Colombia

Sin embargo, el conjunto de núcleos educativos no se agota allí. A lo largo de los 25 años de vida de la CLOC-VC, se han consolidado una veintena de instancias de formación en Nuestra America; ${ }^{4}$ y es bajo los principios fundamentales del proyecto político-pedagógico de la CLOC-VC (internacionalismo, praxis, organicidad y el vínculo comunitario con el trabajo en territorio) que se fortalecen estos ámbitos como trincheras de lucha contrahegemónica.

Entre los preceptos principales de este desarrollo educativo, la educación campesina presupondrá cuatro elementos centrales que describen este formato de educación rural como dispositivo de lucha política. Esto es, siguiendo a Rosset y McCune (2019): 1) el diálogo de saberes, diálogo horizontal entre los diferentes tipos de conocimientos y saberes, 2) la integración holística de la formación técnico-agroecológica con los valores políticos, 3) la alternancia de los tiempos en la escuela con los tiempos en la comunidad; 4) el diseño de todos los espacios físicos y temporales de la

4 vc ha elaborado un informe del conjunto de espacios pedagógicos que han surgido de la lucha en estos años, en el cual se detallan de manera interactiva las escuelas del campo, las licenciaturas, las maestrías de educación del campo, los Institutos Latinoamericanos de Agroecología (IALA) y demás centros de formación campesina (La Vía Campesina, 2019). 
experiencia escolar (horas de trabajo en finca, el mantenimiento del espacio, entre otros) y 5) la noción de la agroecología y soberanía alimentaria como elementos fundamentales para la resistencia campesina.

En síntesis, la arista pedagógico-política de la CLOC-vc contribuye, por un lado, a denunciar el capitalismo en las fronteras de la nueva ruralidad latinoamericana, mientras por otra parte anuncia un modelo alternativo de organización campesina y popular. Para ello, la masificación de la formación política y agroecológica permite pensar en la "multiplicación de los intelectuales orgánicos de los movimientos sociales" (La Vía Campesina, 2015, p. 7).

\section{Resultados}

\section{Traspaso de la Secretaría Operativa de la CLOC-VC}

En los últimos años, la intensificación de la lucha campesina y popular ha colocado las reivindicaciones de la CLOC-vc (soberanía alimentaria, reforma agraria y agricultura campesina-indígena, entre otras) como eje fundamental en la articulación de muchos de los nuevos movimientos sociales-populares que impugnan el neoliberalismo, la colonialidad y el patriarcado en América Latina. Uno de los signos de la potencialidad que circunda la emergencia subalterna en la CLOC radica en su funcionamiento democrático de base, direccionado por una lógica de rotación en la coordinación interna de las acciones y tácticas del movimiento campesino. Como consecuencia de esa premisa metodológica y política, el 21 de marzo del 2013 se materializó, en un acto emotivo cuya consigna política fue: "Contra el capital y el imperio, por la soberanía de nuestros Pueblos, América lucha" (Pinto, 2013, p. 227), el traslado de la Secretaría Operativa de la CLOC-vc desde la ecuatoriana Federación Nacional de Organizaciones Campesinas e Indígenas (Fenocin) al Movimiento Nacional Campesino Indígena (MNCI) de Argentina.

¿Qué significa este traslado de coordinación? Para comprenderlo, debemos dar cuenta de la implicancia que tiene la conceptualización política de la cuestión campesina en un país como Argentina (Soto, 2018a) y la emergencia de territorialidades abrazadas por los movimientos sociales rurales en esta región latinoamericana (Domínguez, 2012; Soto, 2018b).

\section{Un caso de estudio para entender el traspaso: La Unión de Trabajadores Sin Tierra}

Para principios del 2013, el año de traspaso de la Secretaría Operativa de la CLOC-VC, Argentina se encontraba presidida por Cristina Fernández de Kirchner. El kirchnerismo, como fenómeno político, si bien respondía 
en principio a una gramática política desde arriba, evidenciaba en su vinculación territorial con las demandas de las clases populares una articulación política consistente con algunos movimientos rurales y urbanos (Soto, 2018a). Por aquellos días, al menos primaba cierto optimismo en la retórica movimientista de las organizaciones populares, muchas de las cuales destacaban el crecimiento de sus espacios a partir de la articulación que había permitido, en la coyuntura, superar posturas sectoriales (Natalucci, 2011).

Sobre la articulación de la lucha cotidiana y los horizontes políticos que atraviesa particularmente la fisonomía del campesinado como clase organizada, Diego Montón, militante de la CLOC-Vc y la ust, nos ratifica esa intuición:

Claro, está la resolución cotidiana, que es un nivel, y después está la disputa en términos de recursos, de capital de tierra, que es otro nivel, y muchas veces eso encuentra su límite por un lado, o entra en tensión con la dinámica institucional, que muchas veces está forjada o atravesada por toda la concepción liberal, por la concepción de la propiedad privada y su dinámica absoluta, entonces hay tensiones. Nosotros creemos que el movimiento social, territorial, debe involucrarse en la cuestión política, y creemos que el gran desafío tiene que ver con eso, con cómo encontrar equilibrio donde esas tensiones encuentren canales en los que resolverse en el camino, y ahí pensamos además que la cuestión política no puede ser sectorial, no hemos visto que un partido político sectorial pueda existir, sino que ahí queremos que el movimiento social interactúe con un frente político que seguramente representará una diversidad de situaciones. Bueno en eso está la búsqueda, y también las condiciones hoy en la Argentina nos está llevando a un punto del cual un movimiento social no puede quedar ajeno. (Montón, entrevista realizada el 4 de julio del 2018)

En gran medida, las acciones del movimiento campesino por estos años pusieron en tensión la inquietud respecto de si es posible hablar de un proceso de apertura desde la autonomía o la lucha social (el movimiento de reivindicaciones sectoriales del orden societal-rural) a la construcción de hegemonías alternativas, o si por el contrario la propuesta del movimiento popular no ha logrado erosionar las capas burocráticas del Estado capitalista, pese a cierta direccionalidad de los últimos años hacia la inclusión social y la redistribución de parte de la riqueza generada. Este debate resulta amplio y en permanente resignificación en el armazón político de la CLOC-VC; si bien no nos detenemos en esta tangente, creemos que la dimensión pedagógica de los movimientos aporta conceptos para pensar las anticipaciones de sentido y la lucha social que lleva a cabo el movimiento popular. Sobre esto es que la Educación Campesina ejercitada por el MNCI y en particular por la ust nos aportará algunos elementos de comprensión. 


\section{La ust y las tramas de educación emancipatoria en Nuestra América}

El entramado agrario argentino presenta una estructura cuya característica central hemos Ilamado diversificación abismal de la vida rural (Soto, 2019a): sectores campesino-indígenas por debajo de una frontera de subsistencia resisten a grandes bloques económicos agrarios dedicados a la explotación de tierras, la exclusión del sujeto campesino, el arrendamiento especulativo y la exportación a gran escala de cereales, carne y producción oleaginosa (preferentemente ubicados en el sector centro-este del país conocido como pampa húmeda). En ese contexto, la cloc ve surgir una de sus organizaciones de base fundamentales:

La UST es una organización provincial, tiene 5 regionales. Cada regional nuclea comunidades organizadas, no se trata de la totalidad de la comunidad sino de un grupo de familias que tiene vínculos con la comunidad. Por ejemplo, hay una comunidad Ilamada: La Estación, está en Jocolí, es parte de la regional oeste. En esa comunidad viven 35 familias de las cuales 15 están organizadas y 20 no. Aunque en manifestaciones como el pedido por el acceso al agua para la comunidad, todos participan. No tenemos un número a punta de lápiz fino. Pero, calculamos que somos alrededor de 2800 familias organizadas. (Greco, entrevista realizada el 18 de octubre del 2017)

La UST surgió en el año 2002, cuando la crisis económica producida como consecuencia de las políticas neoliberales de los años noventa dejaba coletazos en la ruralidad local. Para entonces puesteros, agricultores, crianceros y pequeños productores rurales que habían perdido sus tierras, en conjunto con un grupo de activistas e ingenieros agrónomos vinculados a sectores estudiantiles/profesionales de las ciencias agrarias, dieron cuerpo a la Unión de Trabajadores Rurales Sin Tierra.

Mendoza es un espacio marcado por el despojo (Soto, 2018b), como lo demuestran las pericias de resistencias territoriales de las organizaciones populares. ${ }^{5}$ En los últimos años ha tenido lugar en Argentina y América Latina, tanto en el estudio de los movimientos sociales como en la práctica misma de las luchas populares, una ebullición relevante de procesos formativos de los movimientos, que han desarrollado distintas elaboraciones teóricas orgánicas a los procesos políticos en curso (Barbosa, 2015; 2016; Greco et al., 2019; Guelman y Palumbo, 2019; Michi, 2010; Ouviña, 2015; Rosset y Barbosa, 2017; Soto, 2019b) entre las que resalta la emergencia de una disputa epistémica llevada a cabo por los movimientos sociales-populares

5 Existe una amplia documentación de estos procesos, entre otras la llevada a cabo por el grupo de trabajo de la Facultad de Ciencias Políticas y Sociales de la Universidad Nacional de Cuyo: Saberes y territorio: la disputa de sentido desde los movimientos sociales /Código sIIP: F-027. (UNCuyo, 2016). 
en la construcción de saberes y formas de educación popular alternativa. En particular el reciente trabajo de Val et al. (2019) sintetiza los dispositivos de lucha política que lleva a cabo la CLoc-vc a través de las nociones de soberanía alimentaria y agroecología (Rosset et al., 2019). La ust expresa en gran medida esta emergencia; es preciso indagar el carácter de las luchas del mundo rural latinoamericano para dar cuenta de las problemáticas que rodean la noción de una pedagogía campesina en términos emancipatorios. A continuación remitimos a las notas obtenidas en nuestra aproximación de investigación militante con la práctica social argentina y las luchas encarnadas por los movimientos de la CLOC-VC, en particular la lucha agraria y popular en sus dimensiones pedagógicas y plebeyas.

\section{Educación campesina: un derecho que camina}

Tal como lo enmarcamos desde el comienzo, la conformación de articulaciones globales con implicancias territoriales locales resulta ser, en los últimos años, la grieta por donde emergen denuncias y alternativas a la hegemonía del capitalismo financiero que domestica territorios y desplaza a los pueblos trabajadores de la tierra. El proyecto pedagógico-político altermundista de la CLOC-VC encarna la posibilidad de construcción de "otras pedagogías" surgidas de la lucha tal como hemos mencionado aquí. El reclamo por la tierra en el centro-oeste de Argentina también se hilvana en nuevas pedagogías insumisas que construyen una episteme campesina/ indígena a partir de un sujeto histórico-plural, pero no menos orgánico, a la defensa de la soberanía alimentaria y la seguridad de los pueblos.

La ust presenta modalidades de insumisión en clave de las prácticas prefigurativas iniciadas en el periodo en el que la CLOC asumió tareas protagónicas en el debate público del Cono Sur: su proyecto pedagógico-político y su resistencia territorial dan cuenta de ello. Sobre esto último, Marta Greco $^{6}$ define a la organización con mayor precisión:

La Unión de Trabajadores Sin Tierra (UST) es una organización base del Movimiento Nacional Campesino Indígena ( $\mathrm{MNCl}$ ) que tiene un desarrollo territorial en casi todo el país. Tenemos una propuesta política pedagógica que se materializó en el surgimiento de Escuelas Campesinas de Agroecología, cuya primera experiencia en la provincia de Mendoza fue en el 2011. Dentro de la ust se ha priorizado la lucha por el acceso a la educación pública, que relacionamos con el acceso a diferentes tipos de conocimientos y bienes culturales, con la formación para el trabajo y para la participación política, con la manera de producir y organizarse. (Greco, entrevista realizada el 18 de octubre del 2017)

6 Militante y educadora popular, integrante del Colectivo de Coordinación Político Pedagógico de la Escuela Campesina de Agroecología y del Centro de Educación, Formación e Investigación Campesina (Cefic-Tierra).

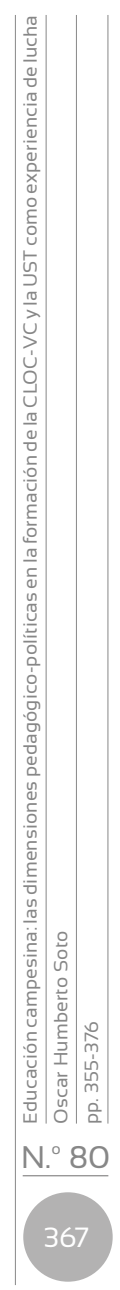


La concepción pedagógica colonial (Puiggrós, 2019) extiende su hegemonía hasta la actualidad, en especial en el área de influencia rural donde las prácticas educativas reproducen la legitimación del orden socioeconómico vigente. La Ust, ya con sus 18 años de existencia, desarrolla en el marco de los principios que estructuran su lucha (la Reforma Agraria Popular, la Soberanía Alimentaria y la Justicia Social) procesos de formación y educación como parte de un proyecto de sociedad mayor (Greco et al., 2019; Soto, 2019a). Su propuesta pedagógica, a través de la Escuela Campesina de Agroecología (ECA) y el Cefic-Tierra — denominación general que aglutina las modalidades de educación tanto media como superior, es decir bachilleratos y estudios terciarios- constituye una modalidad de lucha por un tipo de reforma agraria integral, y hace suya una pedagogía liberadora latinoamericana (Freire, 1983; Soto, 2018c) que permite un genuino diálogo de saberes y donde la articulación teórico-práctica conforma una identidad sólida de sujetos subalternizados en proceso de lucha rural.

La Escuela surgió, como toda organización, por una necesidad. La necesidad era concreta: construir una escuela para incluir al sujeto campesino indígena. Su origen data de un relevamiento que realizó la Unión de Trabajadores Rurales sin Tierra (UST) dentro de la provincia de Mendoza. La ust tiene su sede central en Lavalle, aunque tiene adicionales en toda la provincia. Entonces, el relevamiento se hizo en el territorio y se desarrolló en un periodo de casi 9 meses. (Greco, entrevista realizada el 18 de octubre del 2017)

Esto último es lo que le da pertenencia a la experiencia pedagógica de la ust en el MNCI y la CLOC-VC. Se trata de proyectos de formación pedagógicos reconocidos, muchos de ellos de manera oficial, ${ }^{7}$ pero gestionados por el movimiento popular:

El relevamiento ${ }^{8}$ se centró en el sujeto: ¿Para qué y por qué una escuela? ¿Para qué formarse y contra quién? ¿Para quién era la escuela? ¿Qué queríamos a través de la escuela? ¿Por qué construir una escuela, si la educación es un derecho? El trabajo de base giró a través de estos puntos claves. Puntos, que hoy por hoy constituyen una propuesta política pedagógica de educación popular. La escuela no sólo es para Lavalle, sino que participan Departamentos de toda la provincia. La idea fue incluir otras realidades rurales... Conviven distintos tipos de producción e incluye al sujeto de campo, pero también al de ciudad. La idea surge

7 El Gobierno local posee un conjunto de modalidades oficiales que genéricamente se pueden inscribir en el rubro de "gestión social". En este caso, el Estado paga salarios docentes y el movimiento social organiza los espacios, la estructura y el lineamiento educativo.

8 La idea de relevamiento aquí se expresa como estudio con las poblaciones rurales lindantes al movimiento a través de encuestas y entrevistas con las familias campesinas e indígenas. 
en el 2010 pero comenzó a concretarse en el 2011. En el presente año se estaría egresando la quinta camada de alumnos. (Greco, entrevista realizada el 18 de octubre del 2017)

La educación propuesta desde el Cefic-Tierra, en cuanto espacio integral en el que se nuclea la propuesta pedagógica de la UST, parte de las necesidades que se dan en el lugar donde viven los campesinos, respetando el conjunto de sus concepciones culturales, a partir de sus experiencias y su vida cotidiana concreta (Greco y Peterle, 2017). La ECA tiene en la alternancia ${ }^{9}$ su principio fundamental en el ejercicio del derecho a la educación en el campo. Esta dimensión pedagógica de la alternancia se organiza en dos tiempos: el Tiempo Escuela (TE) y el Tiempo Comunidad (TC), ambas dinámicas en mutua relación y complemento (Martínez y Rosset, 2016). El cursado de la ECA y la formación política en el Cefic-Tierra respeta la identidad de los campesinos, habitantes de comunidades locales, además de fortalecer y legitimar sus saberes para evitar el desarraigo.

Concretamente dentro del esquema curricular de la ECA existe una materia (espacio curricular) Ilamada Tiempo en Comunidad, a cargo de tres coordinadores durante los tres años de escuela. En este espacio se busca recuperar los saberes del tiempo en la comunidad de base y reflexionar sobre la experiencia de aprendizaje de los estudiantes. De alguna manera, se da en los hechos una pedagogía campesina política-agroecológicamente emergente (Rosset, 2019).

|El contexto del surgimiento de la ECA de la ust está relacionado con la necesidad de jóvenes y adultos de continuar y concretar procesos de formación, dada la falta de ofertas educativas en los territorios rurales del norte de la provincia de Mendoza. A su vez, se propone como un elemento central de formulación de un proyecto pedagógico político sustentado en la agricultura campesina/indígena y la agroecología en oposición a la agricultura industrial y el agronegocio. (Greco, entrevista realizada el 18 de octubre del 2017)

El Tiempo Escuela y el Tiempo en Comunidad, en definitiva, se complementan y construyen como un espacio político-pedagógico que problematiza las relaciones entre tierra, territorio, trabajo y producción campesino-indígena para construir alternativas colectivas desde y con las comunidades. Surge, en suma, por parte de un sector invisibilizado que emerge con fuerza organizativa y exige, a través de su praxis y sus organizaciones populares, una ruptura esencialmente política o de esa forma primordial en la que se condensan las resistencias sociales, tal como proponía Rene Zavaleta Mercado (1982).

9 En referencia a la alternancia existe una íntima vinculación de estas experiencias, relatadas en el marco de la CLOC-VC, con la metodología, la especialidad y la finalidad que el MST estableció de manera pionera en Brasil (Gomes de Mattos y Do Nascimento, 2014). 


\section{Disputar el territorio y las subjetividades}

El traspaso político de la CLOC-VC y el trabajo del movimiento campesino argentino han sido un punto clave de la acumulación histórica de estas organizaciones de base rural. Recientemente se llevó a cabo el ı Seminario Internacional de Formación y Política Agraria (Soto, 2019b) organizado por la UST. Este encuentro de organizaciones y movimientos sociales latinoamericanos desarrollado en Lavalle (Mendoza) fue un momento propicio para repensar colectivamente las experiencias de formación e itinerarios pedagógicos de la Vía Campesina, los interrogantes sobre las políticas públicas para una educación emancipadora, el surgimiento de gramáticas nuevas en las luchas por la agroecología, la tierra y la soberanía alimentaria, y las miradas sobre la producción, distribución y formas de organización de los movimientos populares. En ese marco tuvo lugar la inauguración formal del Centro de Educación, Formación e Investigación Campesina, que ya hemos mencionado.

Desde el 2010 la ust Ileva a cabo en Jocolí, Lavalle, tareas de formación colectiva que se han forjado al calor de las disputas frente al Estado y las lógicas mercantiles que rodean todo lo referente al proceso educativo. Activos de esas luchas son la ECA, la Tecnicatura en Economía Social y Desarrollo Local y el Profesorado en Educación Primaria, entre otras modalidades de educación popular del campesinado local. Cerca de 200 educandos ya han transitado instancias formativas ancladas en esta dinámica pedagógica, tal como propone la CLOC-VC a escala global.

La alternancia, referente de la formación del Cefic-Tierra, viene a cuento de nuestro argumento ya que implica sistematizar los tiempos intermitentes de la educación campesina, Tiempo Escuela/Tiempo en Comunidad. Esta articulación permite brindar a los estudiantes elementos teóricos para la praxis comunitaria y la autoeducación en los territorios, en el trabajo agroecológico y en los espacios de militancia. Disputar políticamente desde el territorio es recrear diversas formas del hecho educativo, y es, a su vez, producir subjetividades que re-pregunten e interpelen los sinsentidos de este momento histórico: ¿Por qué los jóvenes se van del campo? ¿Quién se hace fuerte a partir de nuestro trabajo? ¿Por qué no pasar de la emergencia a una real soberanía alimentaria? ¿Por qué no aunar nuestras místicas y darles cuerpo a nuestros imaginarios rebeldes?

El movimiento campesino ha procurado impugnar las formas descarnadas del recetario neoliberal, mientras al calor de sus quinchos ${ }^{10}$ y hornos de barro ha contagiado una "pedagogía de la osadía" — en palabras de los militantes de la UST—, capaz de ampliar el imaginario utópico para ese otro mundo posible que crece desde abajo. Así como el । Seminario 
Internacional de Formación y Política Agraria sirvió para hacer una puesta en común del proyecto pedagógico-político de La Vía Campesina, este momento colectivo ha permitido recrear legados pedagógicos y darle mayor relieve a la construcción de poder popular que la UST y el MNCI realizan silenciosamente en el territorio. El Cefic-Tierra, entonces, no es otra cosa que esa trinchera territorial y pedagógico-política desde la cual se han hilvanado, y se multiplican, nuevas formas de enunciar la sociedad que queremos, tal como lo defiende históricamente la CLOC-VC.

\section{Conclusiones}

\section{Notas finales}

Los movimientos sociales campesinos/rurales latinoamericanos se caracterizan por el despliegue de un conjunto de prácticas cuya "gramática política" (Natalucci, 2010) ha sido relevante en el proceso de impugnación al capitalismo y su fase neoliberal en América Latina, al tiempo que ha generado disputas y la construcción de poder popular de principios del siglo XXı. La dimensión de las prácticas y acciones de la CLOC-VC adopta una praxis democrática, autónoma y tiene como método fundamental el diálogo de saberes y la democracia de base. Estas se tornan, por tanto, en expresión de una instancia de rearticulación de la resistencia popular. De cara a este proceso, la CLOC crece en el desarrollo de escuelas de formación política de carácter nacional, regional y continental, fortaleciendo a los dirigentes campesinos de todo el continente. También en el plano de la educación crea escuelas de agroecología en todas las regiones, así como IOS IALA, entre otros.

Si el siglo $x x$ ha dado sobradas señales respecto de la urgencia de las reformas agrarias, territoriales, educativas y políticas en Nuestra América, en el nuevo contexto global en el que se consolida la CLOC-vc y sus espacios de base, como la UST, crecen los motivos para desalambrar la tierra, la pedagogía y el latifundio en Argentina y América Latina. Hay toda una semántica que rodea el planteamiento de los movimientos campesinos e indígenas, que alcanza al feminismo (o en todo caso es alcanzado por esa revolución total), y ese es justamente el horizonte de la reproducción material de la vida, el grito del buen vivir que rehúsa despojarse de la memoria viva de los pueblos de Abya Yala.

Como sostiene la UST, si antes se ha luchado para incluir demandas sobre lo público, la desmercantilización de las relaciones sociales, la importancia del reconocimiento de la agricultura familiar y la economía popular, hoy todos los colectivos militantes se encuentran ante la obligación de gestar una nueva articulación global, un nuevo internacionalismo o —como se pronuncia desde el Cefic-Tierra- una nueva "pedagogía de la articu- 
lación y la osadía" que reivindique el derecho a los alimentos sanos en el campo y la ciudad, que conciba los derechos que los campesinos van forjando en las rugosidades de nuestra ruralidad.

A fuerza de lucha y resistencia, la educación popular ha reinventado los caminos para ser un poco más libres e iguales. Las pedagogías de los movimientos populares latinoamericanos se han vuelto una esperanza cuando el mundo despunta desesperanzado; tal vez porque como el mismo Paulo Freire (1983) diría: sin un mínimo de esperanza, no podemos ni siquiera comenzar el embate. Este momento difícil de América Latina nos anima a seguir cultivando una militancia empecinada que se reinvente en el cuidado de la tierra, el poder popular y los proyectos pedagógico-políticos desde abajo.

\section{Referencias}

Barbosa, L. P. (2015). Educación, resistencia y movimientos sociales: la praxis educativo-política de los Sin Tierra y de los Zapatistas (tesis doctoral). Universidad Nacional Autónoma de México, Programa de Posgrado en Estudios Latinoamericanos, México. http://www.reformaagrariaemdados.org.br/sites/default/files/Educacion,\%20reistencia\%20y\%20movimentos\%20sociales\%20-\%20la\%20praxis\%20 educativo-politica $\% 20 \mathrm{de} \% 20$ los $\% 20 \mathrm{Sin} \% 20 \mathrm{Tierra} \% 20 y \% 20$ de\%20los\%20Zapatistas.pdf

Barbosa, L. P. (2016). Educación, resistencia y conocimiento en América Latina: por una teoría desde los movimientos sociales. De Raíz Diversa, 3(6), 45-79.

Barbosa, L. y Rosset, P. (2017) Movimentos sociais e educaçao do campo na America Latina: Aprendizagens de um percurso historico. Práxis Educacional, 13(26), 22-48.

Bartra, A. (2010). Campesindios. Aproximaciones a los campesinos de un continente colonizado. Memoria, 248, 4-13.

Coordinadora Latinoamericana de Organizaciones del Campo-Cloc. (2010). ¿Quiénes somos? http://www.cloc-viacampesina.net/institucional/quienes-somos

Domínguez, D. (2012). Recampesinización en la Argentina del siglo xxI. Psicoperspectivas. Individuo y Sociedad, 11(1), 134-157. 10.5027/ psicoperspectivas-Vol11-Issue1-fulltext-167.

Coordinadora Latinoamericana de Organizaciones del Campo-CLOC. (2014a). Convocatoria hacia el 6. ${ }^{\circ}$ Congreso de la ClOC. http:// www.cloc-viacampesina.net/convocatoria-hacia-el-6to-congreso-de-la-cloc

Coordinadora Latinoamericana de Organizaciones del Campo-CLOC. 
(2014b). Campesinos y campesinas, indígenas y trabajadores del campo y de la ciudad de la CLOC-VC celebramos junto a los zapatistas. http://www.cloc-viacampesina.net/campesinos-y-campesinas-indigenas-y-trabajadores-del-campo-y-la-ciudad-de-la-cloc-vc-celebramos

Coordinadora Latinoamericana de Organizaciones del Campo-CLOC. (2015). Documento de trabajo interno de la cloc. http://www.cloc-viacampesina.net/

Freire, P. (1983). Pedagogía do Oprimido. Paz e Terra.

Giarraca, N. (2017). Estudios rurales y movimientos sociales: miradas desde el Sur. Antología esencial. Clacso.

Giraldo, O. y Rosset, P. (2016). La agroecología en una encrucijada: entre la institucionalidad y los movimientos sociales. Guaju, Matinhos, 2(1), 14-37.

Gomes de Mattos, R. y Do Nascimento, G. (2014). Educação do MST e crise do paradigma moderno de ciência. Revista Brasilera de Educação, 19(59), 1077-1099.

González Casanova, P. (2001). Los zapatistas del siglo Xxı. OSAL, Observatorio Social de América Latina. http://biblioteca.clacso.edu.ar/ar/ libros/osal/osal4/analisis.pdf

Greco, M. y Peterle, R. (2017). La educación superior campesina. Trama y Contraluz, 2, 17-28. https://tramaycontraluz.com/2017/11/04/ la-educacion-superior-campesina/

Greco, M.; Peterle, R.; Couto, S.; Bonomo, C. y Soto, O. (2019). Educación rural y territorios en disputa: La alternancia como propuesta pedagógica. Revista de Estudios de Extensión en Humanidades. 6(7). https://revistas.unc.edu.ar/index.php/EEH/article/view/24187/23596

Guelman, A. y Palumbo, M. (2019). La construcción de pedagogías descolonizadoras: notas desde la praxis del trabajo en organizaciones sociales. Revista Colombiana de Educación, 76, 33-49.

La Vía Campesina. (2007). Declaración de Tlaxcala de La Vía Campesina. ॥ Conferencia Internacional de La Via Campesina. Tlaxcala, Mexique, 18 al 21 de abril de 1996. https://viacampesina.org/es/ii-conferencia-internacional-de-la-via-campesina-tlaxcala-mexique-18-al-21-abril-1996/

La Vía Campesina. (2013). Argentina: Traspaso de la Secretaría Operativa de la ClOc-Vía Campesina. https://viacampesina.org/es/argentina-traspaso-de-la-secretaria-operativa-de-la-cloc-via-campesina/

La Vía Campesina (2015). Agroecología campesina. Por la soberanía alimentaria y la Madre Tierra. Experiencias de La Via Campesina. Cuaderno, 7. https://viacampesina.org/es/wp-content/uploads/sites/3/2015/11/CUADERNO\%207\%20LvC\%20ESPANOL.compressed.pdf

La Vía Campesina (2019). La Vía Campesina: escuelas y procesos de formación en agroecología. https:/viacampesina.org/es/escuelas/ 
Larrea Maldonado, A. (2004). El Movimiento Indígena Ecuatoriano: participación y resistencia. OSAL, Observatorio Social de América Latina, 5(13). http://biblioteca.clacso.edu.ar/clacso/osal/20110307010944/6Acmaldonado.pdf

León, O. (2019). Cloc 25 años. Revista América Latina en Movimiento, 543(43), segunda época. https://www.alainet.org/sites/default/files/ alem-541.pdf

Mançano Fernandes, B. (2017). Territorios y soberanía alimentaria. Revista Latinoamericana de Estudios Rurales, 2(3). http://www.ceilconicet. gov.ar/ojs/index.php/revistaalasru/article/view/114

Martínez Torres, M. E. y Rosset, P. (2016). Diálogo de saberes en la Vía Campesina: soberanía alimentaria y agroecología. Espacios Regionales, 1(13), 23-36.

Michi, N. (2010). Movimientos campesinos y educación. El Movimiento de los Trabajadores Rurales Sin Tierra y el Movimiento Campesino de Santiago del Estero Mocase-vc. Editorial El Colectivo.

Natalucci, A. (2010). ¿Nueva gramática política? Reconsideraciones sobre la experiencia piquetera en la Argentina reciente. Astrolabio. Nueva Época, 5. https://revistas.unc.edu.ar/index.php/astrolabio/article/ view/180/189

Natalucci, A. (2011). Entre la movilización y la institucionalización. Los dilemas de los movimientos sociales (Argentina, 2001-2010). Polis. Revista Latinoamericana, 28, 1-28.

Ouviña, H. (2015). Educación en movimiento y praxis prefigurativa. Una lectura gramsciana de los proyectos pedagógico-políticos impulsados por los movimientos populares latinoamericanos. En F. Hillert, H. Ouviña, L. Rigal y D. Suárez (eds.), Pedagogías críticas en América Latina: experiencias alternativas de educación popular (pp. 99-148). Noveduc.

Ouviña, H. y Thwaites Rey, M. (2018). Estados en disputa: auge y fractura del ciclo de impugnación al neoliberalismo en América Latina. El Colectivo.

Pinto, L. (2013). Empoderamiento campesino en el agro argentino contemporáneo. Análisis teórico-empírico de una propuesta campesino-indígena para el (otro) agro argentino. Sujetos sociales del agro argentino. Configuraciones históricas y procesos de cambio. En J. Muzlera y A. Salomón (comps.), Sujetos sociales del agro argentino. Configuraciones históricas y procesos de cambio (pp. 223-248). Prohistoria.

Puiggrós, A. (2019). La escuela, plataforma de la patria. Unipe Editorial Universitaria, Clacso.

Rauber, I. (2012). Revoluciones desde abajo. Gobiernos populares y cambio 
social en Latinoamérica. Peña Lillo, Ediciones Continente.

Rosset, P. (2015). Epistemes rurales y la formación agroecológica en la Vía Campesina. Ciencia y Tecnología Social, 2, 1-10.

Rosset, P. (2016). La reforma agraria, la tierra y el territorio: evolución del pensamiento de La Vía Campesina. Mundo Agrario, 17(35). http:// www.memoria.fahce.unlp.edu.ar/art_revistas/pr.7490/pr.7490.pdf

Rosset, P. y Barbosa, L. P (2017). Educação do campo e pedagogia camponesa agroecológica na América Latina: aportes da La Via Campesina e da cıoc. Educação \& Sociedade, 38(140), 705-724.

Rosset, P. y McCune, N. (2019). La Vía Campesina y el desafío de llevar la agroecología campesina a escala territorial: el papel de las escuelas. En A. Ramos Dos Santos, L. Coelho y J. Silva Olivera (org.), Educação e Movimentos Sociais (vol. 4), (pp. 345-374). Paco Editorial,

Rosset, P. y Martínez-Torres, M. (2012). Rural social movements and agroecology: context, theory and process. Ecology and Society, 17(3), 17.

Soto, O. (2017). Territorio, movimientos campesinos y paisajes de resistencia. Breve ensayo desde una lectura de Milton Santos. Crítica y Resistencias, 4, 96-114. http://criticayresistencias.comunis.com.ar/ index.php/CriticaResistencias/article/view/75/37

Soto, O. (2018a). Movimientos sociales y articulaciones políticas. Apuntes sobre el Movimiento Nacional Campesino Indígena y el Movimiento Evita en el período kirchnerista. Millcayac, 5(9), 33-58.

Soto, O. (2018b). Movimientos sociales y recreación de las luchas rurales: campesinos e indígenas en defensa del territorio. Diálogos Mercosur, 5, 171-182. http://www.revistadialogosenmercosur.com/ gallery/13\%20oficial\%20articulo\%20num\%205\%20jul\%20dic\%20 2018diamersul.pdf

Soto, O. (2018c). Freire, Mariátegui y una educación popular campesina. Alainet. https://www.alainet.org/es/articulo/196777

Soto, O. (2019a). Re-existencias y lucha política en América Latina: un registro de las temporalidades campesino/indígena desde el Sur Global. Ciencia Política, 14(28), 103-127. https://doi.org/10.15446/ cp.v14n28.79080

Soto, O. (2019b). Proyectos educativos y movimientos populares en Nuestra América. http://www.biodiversidadla.org/Documentos/Proyectos-educativos-y-movimientos-populares-en-Nuestra-America

Soto, O. (2019c). Zavaleta Mercado y un marxismo situado en Nuestra América. La Haine. https://www.lahaine.org/mundo.php/zavaleta-mercado-y-un-marxismo.

Tapia, L. (2016). Consideraciones sobre el trabajo teórico de Zavaleta a partir de la obra de Marx. En Ouviña y Giller (Eds.), René Zavaleta 
Mercado. Pensamiento crítico y marxismo abigarrado. lealc-uba.

Universidad Nacional de Cuyo-uncuyo (2016). Catálogo de Proyectos de Investigación Secyp. http://www.uncuyo.edu.ar/ciencia_tecnica_y_posgrado/catalogo_investigacion/proyecto/buscar/?unidad academica_id $=6 \&$ convocatoria_id $=\&$ proyecto $=\&$ integrante $=\&$ off set $=10$

Val, V., Rosset, P., Barbosa, L. y McCune, N. (2019). Agroecology and La Via Campesina II. Peasant agroecology schools and the formation of a sociohistorical and political subject. Agroecology and Sustainable Food Systems, 1-20. https://doi.org/10.1080/21683565.2019.1617222

Zavaleta Mercado, R. (1982). Problemas de la determinación dependiente y la forma primordial. En S. Bruna, D. Camacho, E. Faletto, J. C. Portantiero, G. Ramírez, L. Verdesoto, C. Verduga y R. Zavaleta, América Latina: desarrollo y perspectivas democráticas (pp. 55-85). Flacso. 